\title{
PECULIARITIES OF MOTOR ACTIVITY OF RATS IN SIMULATION PHARMACOLOGICAL DEPRESSOGENIC STATES
}

DOI: 10.36740/WLek202109114

\author{
Antonina Sydorenko ${ }^{1}$, Ruslan Lutsenko ${ }^{1}$, Iryna Kniazkova ${ }^{2}$, Nataliia Liakhovska ${ }^{1}$, Olga Lutsenko ${ }^{1}$ \\ 'POLTAVA STATE MEDICAL UNIVERSITY, POLTAVA, UKRAINE \\ 2KHARKIV NATIONAL MEDICAL UNIVERSITY, KHARKIV, UKRAINE
}

\begin{abstract}
The aim: To analyze and compare the features of changes in the motor activity of rats on the background of pharmacological models of depressive disorders. Materials and methods: Depressive-like state was simulated on 40 mature male Wistar rats using: reserpine (15 mg/kg), clonidine $(0.1 \mathrm{mg} / \mathrm{kg})$, haloperidol $(0.25 \mathrm{mg} / \mathrm{kg})$. The control group was given as a single dose $0.5 \mathrm{ml}$ of a $0.9 \%$ sodium chloride solution intraperitoneally. After 3, 12, 24, 48 and 72 hours from the beginning of the experiment, changes in motor activity in the "open field" test were examined by the number of crossed squares, the calculation was carried out within 5 minutes.

Results: Reserpine at a dose of $15 \mathrm{mg} / \mathrm{kg}$ caused probable motor activity disorders in rats in the "open field" test during all study periods. The most pronounced inhibition of motor activity was observed within 12-48 hours from the beginning of the experiment. 3 hours after clonidine administration, the number of crossed squares decreased by $310 \%$ ( $p<0.001)$, after 12 hours - by 180\% ( $<<0.001)$, after 24 hours - by 140\% ( $p<0.001)$, after 48 hours - by 50\% ( $<<0.005)$ in comparison with the control group. 0n 3 rd day, the motor activity of rats was almost completely restored. The use of haloperidol after 3 hours most significantly impaired the motor activity of rats in the "open field" test, and its recovery was observed after 24 hours.

Conclusions: Reserpine inhibited the motor activity of rats, most pronounced from 12 to 48 hours of the experiment. Clonidine inhibited mainly in the first hours of the study. Haloperidol impaired motor activity at 3rd and 12th hours of observation.
\end{abstract}

KEY WORDS: motor activity, reserpine, clonidine, haloperidol, rats

Wiad Lek. 2021;74(9 p.l):2105-2108

\section{INTRODUCTION}

Depressive disorders and related pathology are extremely common and their number is constantly growing [1]. Therefore, these mental disorders are of great interest to the scientific community, which is to further study the causes, mechanisms of development of depressive pathology and ways of their correction [2]. One of the problems of effective search and study of means for the treatment of depressive disorders is the need to reproduce the changes that occur in human depression in animals [3]. There are various models of reproduction of a depressive-like state in rodents which simulate disorders of a certain part or individual symptoms of this pathology. Unfortunately, none of the models reflects the inner excitement, emotional state and suicidal thoughts, intentions and attempts observed in patients [4].

The desired experimental model of a depressive-like state in rats should reproduce the etiopathogenesis, symptoms and response to treatment similar to the reaction that ill patients have [5].

The Porsolt test, “Tail Suspension Test”, Forced Swim Test are used for screening study of potential antidepressants $[6,7]$. The Porsolt test determines the following indicators: the latency period of the first "hanging" and the total immobility time (sec.), which is interpreted as manifestations of depression. The "Tail Suspension Test" is a "dry" analogue of the Porsolt test. The time is recordered when the animal reaches the base of the tail with a snout (sec.) [4]. The Forced Swim Test is based on the observation of animals that swim vigorously and try to get out of the water. It is investigated: the number of wheel movements per minute and the time of its immobility (sec.). At the same time, the beginning of the immobility stage is interpreted as a manifestation of "despair" [8]. Behavioral tests are informative in the initial assessment of the antidepressant activity of compounds with a single administration and are beneficial at the screening stages and are not specific for long-term use of a potential antidepressant. This is one of their main drawbacks because in humans the effects of antidepressants are manifested precisely with long-term administration, since depression is a chronic disease.

Such models of depressive disorders as prenatal stress, postnatal stress, early social isolation, chronic moderate stress and dexamethasone testing are long-lasting, they do not always meet bioethical standards and only partially reproduce depressive disorder $[9,10]$.

Sufficiently informative and accessible models for studying the mechanisms of action of potential antidepressants are pharmacological models that allow to evaluate the effectiveness of the studied substances and to establish possible mechanisms of action of the potential drug $[8,11]$. 


\section{THE AIM}

The aim of the work - is to analyze and compare the features of changes in motor activity in rats against the background of pharmacological models of depressive disorders.

\section{MATERIALS AND METHODS}

The experiments were performed on 40 adult male rats weighing 150-200 g, under standard conditions in the afternoon in spring and in compliance with the recommendations of the European Convention for the Protection of Vertebrate Animals Used for Experiments and Other Scientific Purposes (Strasbourg, 1985), the Law of Ukraine On the Protection of Animals from Cruel Treatment (No. 3446 - IV 21.02.06).

Experimental depressive state was reproduced by using: reserpine ("Sigma-Aldrich", USA) at a single dose of $15 \mathrm{mg} /$ $\mathrm{kg}$ of body weight intraperitoneally, clonidine ("Clofelin-M" $1 \mathrm{ml}$ of a $0.01 \%$ solution for injection, Kharkiv LLC "Health of the people", Ukraine) at a single dose of $0.1 \mathrm{mg} / \mathrm{kg}$ of body weight intraperitoneally and haloperidol ("Haloperidol-Richter" $1 \mathrm{ml}$ of a $0.5 \%$ solution for injection, "Gedeon Richter", Hungary) at a single dose of $0.25 \mathrm{mg} / \mathrm{kg}$ [8]. The control rats were administered $0.5 \mathrm{ml}$ of saline as a single dose intraperitoneally and introduced into the experiment in the same way as experimental rats. The motor activity of the animals in the "open field" test was investigated after 3, 12, 24, 48 and 72 hours from the beginning of the experiment, the number of crossed squares was counted within 5 minutes of the animal's stay in the installation. The "open field" test is a 140x70 cm rectangular field divided into $10 \times 10 \mathrm{~cm}$ squares and illuminated by a $100 \mathrm{~W}$ light bulb [12].

Statistical processing of the study results was performed using Microsoft Statistika 6.0 software using the nonparametric Mann-Whitney criterion.

\section{RESULTS}

Experimental reproduction of depression testified that the administration of reserpine $(15 \mathrm{mg} / \mathrm{kg}$ ) had led to the inhibition of the motor activity in animals during testing them in the "open field". It has been found that after 3 hours there was a decrease in the number of crossed squares by $140 \%(\mathrm{p}<0.001)$, after 12 hours - by 490\%; ( $<<0.001)$, a day after the beginning of the study the value of motor activity decreased by $230 \%(\mathrm{p}<0.001)$ in comparison with the indicators in the control group of rats. After 2 days from the beginning of the experiment, there was a decrease in the number of crossed squares in the "open field" test by $220 \%(\mathrm{p}<0.001)$ compared to the indicators of the control group. On the 3 rd day after reserpine administration, the number of crossed squares decreased by $120 \%(\mathrm{p}<0.001)$ compared with the control pathology. As a result of conducted investigation it has been found that motor activity in rats on the background of plant neuroleptics was suppressed during the entire study period but most significantly at 12 and 48 hours from the beginning of the experiment. It should be noted that in the last period the indicator slowly tends to recovery (table I).

The use of the central $\alpha$-adrenomimetic clonidine in experimental rats has also resulted in impaired motor activity of rats.
During the first observation period the number of crossed squares decreased by $310 \%(\mathrm{p}<0.001)$ relative to the values in the animals of the control group. After 12 hours, the number of crossed squares decreased by $180 \%$ ( $p<0.001)$ compared to the indicators of the control group. One day later, the number of crossed squares under the influence of clonidine decreased by $140 \%$ ( $\mathrm{p}<0.001)$ compared with rats of the reference group. The use of clonidine 48 hours after the beginning of the experiment contributed to the inhibition of motor activity by $50 \%(\mathrm{p}<0.005)$ relative to the values of the indicator in the control. Thus, under the influence of clonidine, the number of crossed squares in the "open field" test changed. Motor activity changed most significantly 3 hours after administration of central $\alpha$-adrenomimetic and lasted until the end of the first day. The complete recovery of motor activity of rats was observed in the "open field" test after 72 hours of clonidine administration (table I).

The use of the neuroleptic haloperidol significantly altered the motor activity of rats in the "open field" test. Thus, after 3 hours, the number of crossed squares decreased by $860 \%$ ( $p<0.001)$ relative to the control values. On the background of haloperidol after 12 hours there was an inhibition of motor activity by $110 \%$ $(\mathrm{p}<0.001)$ compared with the values during the introduction of saline. One day after the beginning of the experiment, the introduction of a neuroleptic reduced the number of crossed squares by $50 \%(\mathrm{p}<0.02)$ relative to the values in the control group. Further investigation revealed a gradual recovery of the number of crossed squares in rats in the "open field" test. This neuroleptic caused the most pronounced violation of motor activity in the first observation period from the beginning of the experiment. On the background of haloperidol, the complete recovery of motor activity in rats occurred at the end of the first day of the experiment.

When comparing violations of motor activity of rats observed with the use of pharmacological agents in the "open field" test, it was found that in 3 hours clonidine inhibited motor activity by $70 \%$ more relative to the values of the indicator during reserpine administration. The use of clonidine after 48 and 72 hours increased the number of crossed squares by an average of $100 \%(\mathrm{p}<0.001)$ relative to the values on the background of reserpine. 3 hours after administration of haloperidol, motor activity decreased by $290 \%$ ( $\mathrm{p}<0.001)$ relative to the indicator in rats that were administered a plant neuroleptic. On the background of haloperidol after 24 hours, motor activity increased by $130 \%(\mathrm{p}<0.01)$, after 2 days this indicator increased by $190 \%$ $(\mathrm{p}<0.001)$ compared to the value when reserpine was administered. In the last observation period on the background of the classic neuroleptic haloperidol, it was observed an increase in the number of crossed squares by $140 \%(\mathrm{p}<0.001)$ in relation to reserpine and motor activity was at the level of the control group (table I).

When comparing the motor activity with haloperidol and clonidine administration, certain differences were also found. In the first observation period after administration of haloperidol a decrease in motor activity was found by $130 \%(\mathrm{p}<0.001)$ relative to the indicators with the clonidine administration. After 12 hours under the influence of haloperidol there was an increase in the number of crossed squares by $40 \%(\mathrm{p}<0.01)$ relative to the use of clonidine. After 24 hours, the effect of haloperidol was 
Table l. Changes in motor activity of rats in the open field test against the background of pharmacological models of depression $(M \pm m, n=10)$

\begin{tabular}{|c|c|c|c|c|c|}
\hline \multirow[t]{2}{*}{ Group of animals } & \multicolumn{5}{|c|}{ Crossed squares } \\
\hline & in $\mathbf{3}$ hours & in 12 hours & in $24 \mathrm{~h}$ & in $48 \mathrm{~h}$ & in $72 \mathrm{~h}$ \\
\hline $\begin{array}{l}\text { 1. Intact + physiological solution and emulsifier } \\
\text { "Tween } 80 \text { " (the control group 1) }\end{array}$ & $124.0 \pm 11.2$ & $103.0 \pm 11.3$ & $91.9 \pm 9.44$ & $93.5 \pm 7.37$ & $92.2 \pm 6.25$ \\
\hline 2. Intact + Reserpine, 15 mg/kg (group 2) & $50.5 \pm 6.60$ & $34.7 \pm 5.23$ & $27.5 \pm 7.46$ & $29.0 \pm 3.25$ & $41.3 \pm 4.55$ \\
\hline P1-2 & $<0.001$ & $<0.001$ & $<0.001$ & $<0.001$ & $<0.001$ \\
\hline 3. Intact + Clonidine, 0.1 mg/kg (group 3) & $30.2 \pm 4.46$ & $36.2 \pm 2.78$ & $38.3 \pm 4.13$ & $63.0 \pm 5.57$ & $93.3 \pm 6.44$ \\
\hline P1-3 & $<0.001$ & $<0.001$ & $<0.001$ & $<0.005$ & $>0.05$ \\
\hline P2-3 & $<0.02$ & $>0.05$ & $<0.05$ & $<0.001$ & $<0.001$ \\
\hline 4. Intact + Haloperidol, 0.25 mg/kg (group 4) & $12.9 \pm 0.99$ & $49.4 \pm 3.2$ & $63.0 \pm 4.7$ & $85.4 \pm 6.80$ & $98.7 \pm 8.2$ \\
\hline P1-4 & $<0.001$ & $<0.001$ & $<0.02$ & $>0.05$ & $>0.05$ \\
\hline P2-4 & $<0.001$ & $>0.05$ & $<0.01$ & $<0.001$ & $<0.001$ \\
\hline P3-4 & $<0.001$ & $<0.01$ & $<0.002$ & $<0.05$ & $>0.05$ \\
\hline
\end{tabular}

Note:

$\mathrm{n}$ - the number of animals in the group.

characterized by an increase in the motor activity of rats in the "open field" test by $60 \%(\mathrm{p}<0.002)$, and after 48 hours - by $30 \%$ $(\mathrm{p}<0.05)$ compared to that with the clonidine administration.

\section{DISCUSSION}

It has been found that reserpine caused a decrease in the motor activity of animals in the "open field" test during all periods of the investigation. The effects of reserpine developed gradually and were most pronounced from 12 to 48 hours of the experiment. It is known that the mechanism of depressogenic action of reserpine is due to the irreversible blocking of vesicular monoamine transporter VMAT- 1 and 2 binding. VMAT- 2 is expressed in neurons and its blockade by reserpine inhibits the uptake and reduces the stores of norepinephrine, serotonin, dopamine and histamine $[13,14]$. VMAT-2 usually transports free intracellular monoamines at the presynaptic nerve ending to the presynaptic vesicles for further release into the synaptic cleft. Free neurotransmitters are metabolized by monoamine oxidase and catechol-O-methyltransferase, attach to the outer membrane of mitochondria in the terminal axons and do not participate in the transmission of excitation. Thus, reserpine "removes" monoaminergic mediators from neurons, reducing their number and amplitude of release [11, 15]. Noradrenaline (NA) depletion on the background of reserpine occurs in two phases: during the first fast phase $50 \%$ depletion occurs within 20 minutes; this is followed by a slow phase. Restoration of NA uptake occurs 20-48 hours after reserpine administration, whereas it takes about a week to replenish NA stores and the full restoration of NA neurotransmission occurs more than 14 days. Since the action of reserpine affects all monoamines and develops gradually, so it disrupts the motor activity more pronounced and prolonged in comparison with other depressants.

At the same time, the depressogenic effect of clonidine is due to the direct agonistic effect on the $\mathrm{a} 2 \mathrm{C}$ - and $\mathrm{a} 2 \mathrm{~B}$-autoreceptors, which leads to inhibition of the release of other neurotransmitters in the CNS.

The administration of clonidine caused a pronounced inhibition of motor activity of rats in the "open field" test from 3 to 24 hours. Its restoration occurred at 48 hours of the experiment. Obviously, the depressogenic effect of clonidine is due to the direct agonistic effect on $\alpha_{2 C}{ }^{-}$and $\alpha_{2 B}$-autoreceptors, which leads to inhibition of the release of other neurotransmitters in the CNS [16].

Along with the receptor effect, clonidine causes a marked inhibition of monoamine metabolism in the CNS, in particular decreases the release of norepinephrine, dopamine and their metabolic rate especially in the following brain structures: frontal cortex, hypothalamus and striatum. Clonidine inhibits adenylate cyclase and reduces the level of cyclic adenosine monophosphate (cAMP), hyperpolarization of noradrenergic neurons occurs, the intake of calcium ions decreases, all this leads to the suppression of noradrenaline secretion and inhibition of ascending noradrenergic pathways, in particular in locus ceruleus [16].

The use of haloperidol caused a marked decrease in the number of squares crossed in the "open field" test after 3 and 12 hours of observation. Starting from the third term, there was a gradual recovery of motor activity. It is known that haloperidol directly blocks $\mathrm{D}_{-}, \sigma_{-}, 5 \mathrm{HT}-, \mathrm{H}^{-}, \mathrm{M}_{1^{-}}, \mathrm{a}_{1 \mathrm{~A}^{-}}, \mathrm{\alpha}_{2}$ - and NMDA receptors in the striatum of the brain $[17,18]$. The observed inhibition of motor activity was found to be caused by the blockade of postsynaptic $\mathrm{D}_{2}$-receptors in the striatum of the brain. As we can see, the state of $\mathrm{D}_{2}$-receptor function is of primary importance for maintaining motor activity [17]. Since haloperidol has a direct receptor effect, therefore its depressogenic effect is rapid, powerful and short-lived [18].

Thus, the violation of various links of monoaminergic neurotransmission at the stages of synthesis, metabolism, release of mediators at the postsynaptic level cause depressogenic effects in the form of inhibition of motor activity. However, depending on the stage of receptor or mediator disorders, the degree, severity and duration of depressogenic effects differ. For this reason, to establish the effectiveness of potential antidepressants and study their possible mechanisms of action, it is desirable that the substance corrects motor activity having various depressogenic agents. 
Therefore, biologically active substances that can be recommended for the treatment of depression should regulate the key points of this disease, demonstrate the rapid and long-lasting effect in order to increase the effectiveness of treatment and reduce the risk of non-compliance.

\section{CONCLUSIONS}

1. Reserpine caused a decrease in the motor function of rats, which was the most severe within 12-48 hours of experiment clonidine inhibited motor activity from 3 to 24 hours of study, haloperidol reduced motor activity at 3 and 12 hours of observation.

2. Potential antidepressants should prevent impaired motor activity of animals against the background of the development of a depressive state caused by the introduction of reserpine, clonidine, haloperidol, that is, affect the key mechanisms in the pathogenesis of depression.

\section{REFERENCES}

1. Markozova L.M., Linskyi I.V., Baranenko, 0.V. Analiz dynamiky poshyrenosti ta zakhvoriuvanosti na rozlady psykhiky i povedinky vnaslidok uzhyvannia psykhoaktyvnykh rechovyn v Ukraini za period 1990-2014 rokiv [Analysis of the dynamics of the prevalence and morbidity of mental disorders and behavior due to the use of psychoactive substances in Ukraine for the period of 1990-2014]. Psykhiatriia, nevrolohiia ta medychna psykholohiia. 2017;4(1):52-58. (in Ukrainian).

2. Lutsenko R.V.,Sydorenko A.H., Bobyriov, V.M. Anhedonia at experimental models of chronic stress and its correction. Wiad. Lek. 2017;70(4): 745-750.

3. Söderlund J., Lindskog M. Relevance of rodent models of depression in clinical practice: can we overcome the obstacles in translational neuropsychiatry? International Journal of Neuropsychopharmacology. 2018;21(7):668-676.

4. Planchez B., Surget A., Belzung C. Animal models of major depression: drawbacks and challenges. Journal of Neural Transmission. 2019;126:1383-1408.

5. Overstreet D.H. Modeling depression in animal models. Methods Mol Biol. 2012;829: 125-144.

6. Chen Z.D., ChenW.Q., WangZ.Y. etal. Antidepressant-like action of agmatine in the acute and sub-acute mouse models of depression: a receptor mechanism study. Metabolic Brain Disease. 2018;33(5):1721-1731.

7. Bhat S.A., Wani A.L., Ara A. Animal models of depression and their criteria of validation. Journal of Chemical and Pharmaceutical Research. 2014;6(10):123-130.

8. Hromov L.O., Honchar-Cherdakli L.H., Vorozhbyt A.P. et al. Eksperymentalne doslidzhennia pivkulnoi asymetrii antydepresyvnykh efektiv amitryptylinu [Experimental study of hemisphere asymmetry of antidepressant effects of amitriptyline]. Farmakolohiia ta likarska toksykolohiia. 2015;1(42):19-23. (in Ukrainian).

9. Li M., Chou S.Y. Modeling postpartum depression in rats: theoretic and methodological issues. Zoological Research. 2016;37(4):229-236.

10. Willner P. The chronic mild stress (CMS) model of depression: History, evaluation and usage. Neurobiology of stress. 2017;6:78-93.
11. Ikram H., Haleem D.J. Repeated treatment with reserpine as a progressive animal model of depression. Pakistan Journal of Pharmaceutical Sciences. 2017;30(3):897-902.

12. Lutsenko R.V., Vakhnenko A.V., Vlasova E.V. Research of the protection actions of derived 2-oxoindole in acute stress. Wiad. Lek. 2017;70(1):57-61.

13. Yaffe D., Forrest L.R., Schuldiner S. The ins and outs of vesicular monoamine transporters. J Gen Physiol. 2018;150(5):671-682.

14. Ruiz P., Calliari A., Pautassi R.M. Reserpine-induced depression is associated in female, but not in male, adolescent rats with heightened, fluoxetine-sensitive, ethanol consumption. Behavioural Brain Research. 2018;348:160-170.

15. Eiden L.E., Weihe E.VMAT2: a dynamic regulator of brain monoaminergic neuronal function interacting with drugs of abuse. Ann N Y Acad Sci. 2011;1216:86-98.

16. Naguy A. Clonidine use in psychiatry: panacea or panache? Pharmacology. 2016;98:87-92.

17. Ford C.P. The role of $D 2$-autoreceptors in regulating dopamine neuron activity and transmission. Neuroscience. 2014;282:13-22.

18. Yadav P.N., Kroeze W.K., Farrell M.S. Antagonist functional selectivity: 5-HT2A serotonin receptor antagonists differentially regulate 5-HT2A receptor protein level in vivo. The Journal of Pharmacology and Experimental Therapeutics. 2011;339(1):99-105.

\section{ORCID and contributionship:}

Antonina Sydorenko: 0000-0002-9853-5892 ${ }^{D}$

Ruslan Lutsenko: 0000-0003-0277-0458 ${ }^{E, F}$

Iryna Kniazkova: 0000-0003-1970-9346 ${ }^{B}$

Nataliia Liakhovska: 0000-0003-2116-2722 ${ }^{\mathrm{C}}$

Olga Lutsenko: 0000-0001-8049-2786 ${ }^{A}$

\section{Conflict of interest:}

The Authors declare no conflict of interest.

\section{CORRESPONDING AUTHOR \\ Antonina Sydorenko}

Poltava State Medical University

23 Shevchenko st., 36000 Poltava, Ukraine

tel: +380661958590

e-mail: sidorenko.med@gmail.com

Received: 19.09 .2020

Accepted: 02.08.2021

A - Work concept and design, B - Data collection and analysis, C - Responsibility for statistical analysis,

$\mathbf{D}$-Writing the article, $\mathbf{E}-$ Critical review, $\mathbf{F}$ - Final approval of the article 